\title{
Jadresic, Enrique. Blushing; cuando sonrojarse duele. Uqbar Eds. Santiago de Chile, 2009. 136 pp.
}

Los trastornos de ansiedad y sus muchas variantes clínicas se encuentran entre los de prevalencia más alta entre hombres y mujeres en América Latina y a nivel mundial. A pesar de ser causa de mucho sufrimiento personal y de tener un impacto importante sobre el desarrollo emocional y conductual y la autorealización de quienes los sufren, la literatura sobre tratamientos exitosos de estos desórdenes es más bien escasa. Por eso es una grata novedad encontrar el reciente libro Blushing; cuando sonrojarse duele, de Enrique Jadresic, un connotado psiquiatra chileno, que une, a sus habilidades clínicas y docentes, la capacidad de compartir su experiencia personal con el Rubor Facial Patológico (RFP) de manera elocuente, clara y elegante.

En un breve pero rico volumen de 10 capítulos, respaldado por la respectiva bibliografía y prologado por Renato D. Alarcón, Jadresic describe el enrojecimiento facial en el contexto de las manifestaciones del Trastorno de Ansiedad Social, delimitándolo como patología cuando "se desencadena por estímulos psicológicos menores, produce sufrimiento psíquico o interfiere en forma significativa en el desenvolvimiento escolar o laboral, la vida sentimental o las relaciones interpersonales". De esta manera deslinda la ocurrencia clínica de la respuesta evolucionariamente útil de enrojecimiento facial frente a situaciones embarazosas que ocasionalmente sufren todas las personas y que parece ser uno de los mecanismos fisiológicos que propician el cumplimiento de las reglas sociales.

La no siempre acertada "sabiduría popular" adjudica un juicio negativo a las personas que no se avergüenzan cuando hacen mal: "No tiene sangre en la cara"... pero el autor nos hace notar que cuando el enrojecimiento facial aparece inmotivadamente puede paralizar, retrasar o modificar sustancialmente nuestra conducta, dando lugar al retraimiento social y la desesperanza, situación que se agrava por la trivialización con que se maneja el síntoma y por la dificultad para su tratamiento, sea éste psicoterapéutico o con medicación antidepresiva. Así planteado el panorama, Enrique Jadresic comparte con sus lectores su entusiasmo con la solución quirúrgica al alcance de los pacientes: la simpatectomía (cuyos resultados benéficos se conocen desde 1930) practicada hoy mediante la moderna videoendoscopía. El autor comparte su experiencia personal, como paciente, con este procedimiento y luego como colaborador del cirujano en la evaluación y seguimiento de personas, que como él, se someten a simpatectomía torácica endoscópica. Finalmente, reseña la experiencia de cinco personas, describiendo su vivencia de la enfermedad y los resultados de la intervención, sin omitir los efectos indeseables.

Hay tres aspectos notables en esta obra: la rigurosa delimitación de cuándo una respuesta fisiológica se vuelve síntoma y requiere atención; la importancia que presta el autor al reconocimiento y atención del sentido personal de la dolencia, desde la perspectiva de quien la sufre y también de quien la atiende; y la descripción honesta del proceso mental que lo llevó, primero, a compartir su vivencia con colegas y pacientes y, luego, a escribir el libro.

Para emprender esta trayectoria poco usual de auto-revelación (disclosure), manteniendo al mismo tiempo una necesaria distancia y la indispensable objetividad resultante, se requiere un alto nivel de auto-conciencia y autocrítica y bastante coraje.

El autor describe las diferentes etapas de un proceso que le hizo, inicialmente, ocultar o minimizar la relevancia y severidad de su malestar aún frente a sus padres hasta decidirse a hacerlo con ellos, sus familiares y revelarla luego a las personas que evaluaba pre-operatoriamente. Con la publicación del libro, es evidente que Jadresic sale airoso del reto de ser al mismo tiempo paciente y terapeuta, con el beneficio 
de haber enriquecido su perspectiva científica y clínica al constatar personalmente el "dolor" de padecer un malestar psíquico y el inmenso alivio resultado de un tratamiento exitoso.

Blushing...está escrito en un lenguaje claro y elegante pero también al alcance de todo tipo de pacientes. La experiencia docente del autor hace que la información se presente en forma ordenada y gradual y evite los términos melodramáticos con el mismo cuidado que rehúye los tecnicismos. Su lectura es fácil e instructiva, enormemente útil tanto para los profesionales de la salud en general como, lógicamente, los que laboran en el campo de la salud mental y asisten a pacientes ansiosos. El libro se brinda en la mejor tradición de la literatura profesional dirigida al público "laico", ofreciendo valiosísima información para quienes sufren de rubor facial patológico, muchos de ellos en silencio, sin saber de posibilidades terapéuticas a su alcance y, last but not least, para sus familiares, muchas veces angustiados, confusos o frustrados por una entidad con rezagos de vergüenza, fatalismo, desconcierto y misterio.

Marta B. Rondón ${ }^{1}$

1 Médico Psiquiatra. Docente de la Facultad de Medicina Alberto Hurtado, Universidad Peruana Cayetano Heredia. Lima, Perú. 